\section{International Scientific Journal Theoretical \& Applied Science}

p-ISSN: 2308-4944 (print) e-ISSN: 2409-0085 (online)

Year: 2017 Issue: $11 \quad$ Volume: 55

Published: $30.11 .2017 \quad$ http://T-Science.org
Aygul Rustemovna Omarova Lecturer of Propedeutics and Internal disease department International Kazakh-Turkish University by name Yassavi, Kazakhstan omarova_aygul@bk.ru

Sarviniso Islamovna Ibragimova Master of medical science, lecturer of Propedeutics and Internal disease department International Kazakh-Turkish University by name Yassavi, Kazakhstan sarvinsa@mail.ru

\title{
PREVALENCE OF TUBERCULOSIS IN PREGNANT WOMEN (LITERATURE REVIEW)
}

\author{
Abstract: The article considers a literature review of prevalence of tuberculosis and some features of the \\ course in pregnant women. \\ Key words: tuberculosis, pregnancy, prevalence \\ Language: Russian \\ Citation: Omarova AR, Ibragimova SI (2017) PREVALENCE OF TUBERCULOSIS IN PREGNANT \\ WOMEN (LITERATURE REVIEW). ISJ Theoretical \& Applied Science, 11 (55): 268-271. \\ Soi: http://s-o-i.org/1.1/TAS-11-55-34 Doi: crossef https://dx.doi.org/10.15863/TAS.2017.11.55.34
}

\section{РАСПРОСТРАНЕННОСТЬ ТУБЕРКУЛЕЗА ЛЕГКИХ У БЕРЕМЕННЫХ ЖЕНЩИН. (ОБЗОР ЛИТЕРАТУРНЫХ ДАННЫХ)}

Аннотация: В статье представлен литературный обзор частоты встречаемости туберкулеза легких а также некоторые особенности течения у беременных женщин.

Ключевые слова: туберкулез, беременность, распространенность.

\section{Introduction}

Туберкулез является основной причиной смертности от инфекционных заболеваний в мире. Данное заболевание считается почти таким же древним, как человеческая история, чего подтверждают найденные 7000 лет назад следы этого в египетских мумиях, которых описал Гиппократ [1]. Согласно оценкам, в 2015 г. туберкулезом заболели 10,4 млн. человек, в том числе 5,9 млн. (56\%) мужчин, 3,5млн. (34\%) женщин и 1,0млн. (10\%) детей. $60 \%$ новых случаев заболевания приходятся на шесть стран: Индию, Индонезию, Китай, Нигерию, Пакистан и Южную Африку. Как сообщает Всемирная организация здравоохранения (ВО3), в 2015 году были зарегистрированы 1,4 миллиона случаев смерти от туберкулеза. Хотя число смертей от туберкулеза в период с 2000 по 2015 год сократилось на $22 \%$, он остается одной из 10 причин смерти во всем мире[2].

\section{Materials and Methods}

Туберкулез является третьей ведущей причиной смерти среди женщин в возрасте 15-44 лет, который может вызвать бесплодие и негативно влияет на репродуктивное здоровье [3].
По данным ВО3, каждый год около 700000 женщин умирают от туберкулеза. Как сообщают Stettler W, Crowley K. и др. частота активного туберкулеза у беременных составляет от $0,1 \%$ до $1,9 \%$ [4], хотя, точная заболеваемость туберкулезом во время беременности не всегда доступна во многих странах из-за присутствия множества конфоундинг факторов. Вместе с тем ожидается, что заболеваемость туберкулезом среди беременных женщин будет такой же высокой, как и у всего населения, причем, возможно, более высокая заболеваемость в развивающихся странах. Ранее исследование Schaefer сообщило о показателях нового случая туберкулеза - 18-29 на 100000 беременных, которая была аналогичны показателям (19-39 на 100 000), зарегистрированных в городе Нью-Йорк [5]. Однако недавнее исследование в Соединенном Королевстве показало, что частота заболеваемости составляет 4,2 на 100000 беременных [6].

Туберкулез является лидирующей причиной экстрагенитальной смертности во всем мире, большинство из которых в зонах высокого распространения ВИЧ инфекции [7]. В Южной Африке в ходе скринингового исследования было установлено, что распространенность туберкулеза 
среди ВИЧ-инфицированных в 10 раз выше, чем у ВИЧ-неинфицированных беременных женщин [8]. Кроме того, исследования показывают, что ВИЧинфицированные беременные женщины, коинфицированные туберкулезом, в 2,5 раза чаще передают ВИЧ своим детям, а их дети в 24 раза чаще имеют неонатальный туберкулез [9].

Как сообщает Tripathy S.N. c момента появления жалоб пациенток до диагностики туберкулеза проходит значительный промежуток времени из-за низкой чувствительности и длительного времени обработки доступных диагностических инструментов, необходимости множественных посещений и неспецифичности симптомов у беременных женщин, особенно тех, кто инфицирован ВИЧ [10]. В Мексике Golub JE обнаружил, что материнская заболеваемость, неонатальная смертность и крайняя недоношенность значительно выше среди беременных женщин с туберкулезом, которые начали лечение в конце беременности (25-36 недель беременности), в то время как у беременных начавших лечение на ранних сроках были минимальные отрицательные результаты Кроме того, ранний диагноз и лечение туберкулеза уменьшают его передачу членам семьи, в том числе новорожденным [11]. Исходя из этого ясно, что ранняя диагностика и лечение как ВИЧ, так и туберкулеза имеет решающее значение для улучшения как материнского, так и детского здоровья. ВОЗ рекомендует включить лечение туберкулеза и ВИЧ в дородовые услуги и скрининг на туберкулез всех беременных женщин в районах с высокой распространенностью ВИЧинфекции [12].

Хотя наибольшее бремя заражения туберкулеза происходит в странах с низким социальным статусом, сообщается, что в развитых странах наблюдается возрождение туберкулеза за последние несколько лет, главным образом в результате увеличения числа иммигрантов в этих странах. Ретроспективное исследование в Лондоне за 5-летний период-1997-2001 гг. показало увеличение числа беременных женщин с туберкулезом [13]. Другое исследование, проведенное в 2008 году, показало, что национальный уровень заболеваемости туберкулезом во время беременности в Великобритании составил 4,2 на $100 \quad 000$ беременных или примерно 1 на 24000 беременных женщир. Все беременные женщины с туберкулезом в обоих этих исследованиях относились к этническому меньшинству, значительное количество которых недавно иммигрировало в Великобританию[14]. Centers for Disease Control and Prevention передает, что несмотря на снижение уровня заболеваемости туберкулезом в США, число иммигрантов попрежнему подвержено большему риску заражения туберкулезом по сравнению с лицами, родившимися в США [15].

Проспективная серия случаев была исследована в больнице Northwick Park Hospital, больнице общего профиля университета в штате Брент и Харроу в северо-западной части Лондона, тринадцать пациентов были исследованы в течение 30-месячного периода с декабря 1995 года по май 1998 года. Все пациенты были иммигрантами индийского субконтинента или сомалийского происхождения, и их средняя продолжительность пребывания в Великобритании составляла 31 месяц. Распределение по расовому происхождению матерей составляло 466,3 / 100000 для матерей африканского происхождения и 239,1/100 000 для матерей индийского происхождения. 9 из 13 пациентов имели внелегочный туберкулез. Таким образом, было установлено, что туберкулез возникающий во время беременности, распространен среди иммигрантов[16].

Исследователи со времен Гиппократа выразили свои опасения по поводу неблагоприятных последствий туберкулеза при беременности. Считалось, что легочные полости, возникающие в результате туберкулеза, спадают в результате повышенного внутрибрюшного давления, связанного с беременностью. Эта вера была широко распространена до начала четырнадцатого века. Действительно, немецкий врач рекомендовал молодым женщинам с туберкулезом жениться и забеременеть, чтобы замедлить прогрессирование заболевания. Это практиковалось во многих странах вплоть до 19-го века [17], а в начале 20-го века для этих женщин был рекомендован аборт [18, 19]. Однако исследователи, такие как Hedvall и Schaefer не нашли никакой связи неблагоприятного влияния беременности на прогрессирование туберкулеза. Однако, они сообщили, что частая беременность может иметь отрицательный эффект, поскольку она может способствовать рецидивированию или активации скрытого туберкулеза [20].

Имеются противоречивые данные о влиянии туберкулеза на материнские и неонатальные исходы. Некоторые исследования показали, что при своевременном и соответствующем лечении туберкулезная инфекция не оказывает отрицательного влияния на результаты беременности, тогда как другие полагают, что туберкулез во время беременности приводит к неблагоприятныму исходу. В проспективном исследовании в Индии не найдены статистически значимых различий между осложнениями беременности у беременных женщин с туберкулезом по сравнению с контрольной группой [21]. В отличие от результатов вышеупомянутого исследования ретроспективный обзор в Тайване показал, что женщины, у которых 
был диагностирован туберкулез при беременности, имели повышенный риск неблагоприятных исходов беременности по сравнению с беременными без туберкулеза. Однако, был обнаружен значительно высокий процент детей с низким весом, с малым гестационным возрастом [22].

Несмотря на противоречивые результаты разных исследований, своевременная диагностика и лечение туберкулеза во время беременности являются важным фактором, так как, туберкулез по-прежнему является частой причиной материнской заболеваемости и смертности, особенно в контексте коинфекции ВИЧ [23].

\section{Conclusion}

Таким образом, улучшение диагностики и лечения туберкулеза у беременных женщин являются важными мерами по охране здоровья матери и ребенка. Значительная задержка в диагностике туберкулеза среди беременных женщин, а также обследование новорожденного после родов с целью исключить туберкулезную инфекцию часто упускаются. Исходя из этого, эффективное лечение туберкулеза во время беременности и послеродового периода требует многодисциплинарного подхода, включая акушера, педиатра, фтизиатра и врача общественного здравоохранения, а также проведения крупных популяционных исследований изучающих данные факторы.

\section{References:}

1. (2011) Facts about health in African Subregion. Fact sheet N 314 World Health Organisation, 2011.

2. (2016) WHO Library Cataloguing-inPublication Data. Global tuberculosis report 2016. ISBN $978 \quad 92 \quad 4 \quad 156539 \quad 4$. WHO/HTM/TB/2016.13. Geneva 27, Switzerland

3. (2014) World health Organization: Tuberculosis and gender. 2 September 2014.

4. Vo QT, Stettler W, Crowley K. (2000) Pulmonary tuberculosis in pregnancy. Prim Care Update ObGyns. 2000; 7:244-49.

5. Schaefer G, Zervoudakis IA, Fuchs FF, David S. (1975) Pregnancy and pulmonary tuberculosis. Obstetrics and Gynecology. 1975; 46 (6):706-715.

6. Knight M, Kurinczuk JJ, Nelson-Piercy C. (2009) Tuberculosis in pregnancy in the UK. BJOG. 2009;116(4):584-588.

7. Ahmed Y, Mwaba P, Chintu C, Grange JM, Ustianowski A, Zumla A. (1999) A study of maternal mortality at the University Teaching Hospital, Lusaka, Zambia: the emergence of tuberculosis as a major non-obstetric cause of maternal death. International Journal of Tuberculosis and Lung Disease. 1999;3(8):675680.

8. Pillay T, Khan M, Moodley J, et al. (2001) The increasing burden of tuberculosis in pregnant women, newborns and infants under 6 months of age in Durban, KwaZulu-Natal. South African Medical Journal. 2001;91(11):983-987.

9. Hesseling AC, Cotton MF, Jennings $\mathrm{T}$, et al. (2009) High incidence of tuberculosis among
HIV-infected infants: evidence from a South African population-based study highlights the need for improved tuberculosis control strategies. Clinical Infectious Diseases. 2009;48(1):108-114.

10. Tripathy SN. (2003) Tuberculosis and pregnancy. International Journal of Gynecology and Obstetrics. 2003;80(3):247-253.

11. Golub JE, Mohan CI, Comstock GW, Chaisson RE. (2005) Active case finding of tuberculosis: historical perspective and future prospects. International Journal of Tuberculosis and Lung Disease. 2005;9(11):1183-1203.

12. Mnyani CN, McIntyre JA. (2011) Tuberculosis in pregnancy. International Journal of Obstetrics and Gynaecology. 2011;118(2):226231.

13. Kothari A, Mahadevan N, Girling J. (2006) Tuberculosis and pregnancy - results of a study in a high prevalence area in London. Eur $\mathbf{J}$ Obstet Gynecol Reprod Biol 2006;126:48-55.

14. Knight M, Kurinczuk JJ, Nelson-Piercy C, Spark P, Brocklehurst P. (2009) Tuberculosis in pregnancy in the UK. BJOG 2009;116:584-8.

15. (2010) Centers for Disease Control and Prevention. Decrease in reported tuberculosis cases - United States, 2009. MMWR Morb Mortal Wkly Rep 2010;59:289-94.

16. Thorax. (2000) Feb;55(2):129-32.Tuberculosis diagnosed during pregnancy: a prospective study from London. Llewelyn M, Cropley I, Wilkinson RJ, Davidson RN.

17. Snider D., Jr. (1984) Pregnancy and tuberculosis. Chest. 1984;86(3) 
\begin{tabular}{l|lrl|l|ll} 
& ISRA (India) & $=\mathbf{1 . 3 4 4}$ & SIS (USA) & $=\mathbf{0 . 9 1 2}$ & ICV (Poland) & $=\mathbf{6 . 6 3 0}$ \\
Impact Factor: & ISI (Dubai, UAE) $=\mathbf{0 . 8 2 9}$ & PUHL (Russia) $=\mathbf{0 . 2 0 7}$ & PIF (India) & $=\mathbf{1 . 9 4 0}$ \\
& GIF (Australia) & $\mathbf{0 . 5 6 4}$ & ESJI (KZ) & $=3.860$ & IBI (India) & $=\mathbf{4 . 2 6 0}$ \\
& JIF & $\mathbf{1 . 5 0 0}$ & SJIF (Morocco) & $=\mathbf{2 . 0 3 1}$ & & \\
\hline
\end{tabular}

18. Vallejo JG, Starke JR. (1992) Tuberculosis and pregnancy. Clinics in Chest Medicine. 1992;13(4):693-707.

19. Snider DE, Layde PM, Johnson MW, Lyle MA. (1980) Treatment of tuberculosis during pregnancy. American Review of Respiratory Disease. 1980;122(1):65-79.

20. Hedvall E. (1953) Pregnancy and tuberculosis. Acta Medica Scandinavica. 1953;147(supplement 1286):1-101.
21. Tripathy SN. (2003) Tuberculosis and pregnancy. Int J Gynaecol Obstet 2003;80:24753.

22. Lin HC, Chen SF. (2010) Increased risk of low birthweight and small for gestational age infants among women with tuberculosis. BJOG 2010;117:585-90.

1. McIntyre J. (2003) Mothers infected with HIV. Br Med Bull 2003;67:127-35. 